
\title{
$\begin{array}{ll}\text { Research Square } & \begin{array}{l}\text { Preprints are preliminary reports that have not undergone peer review. } \\ \text { They should not be considered conclusive, used to inform clinical practice, } \\ \text { or referenced by the media as validated information. }\end{array}\end{array}$
}

\section{A qualitative study of stakeholder views on the effects of a sugar-sweetened beverages tax on the budgets, dietary intake, and health of lower and higher socioeconomic groups in the Netherlands}

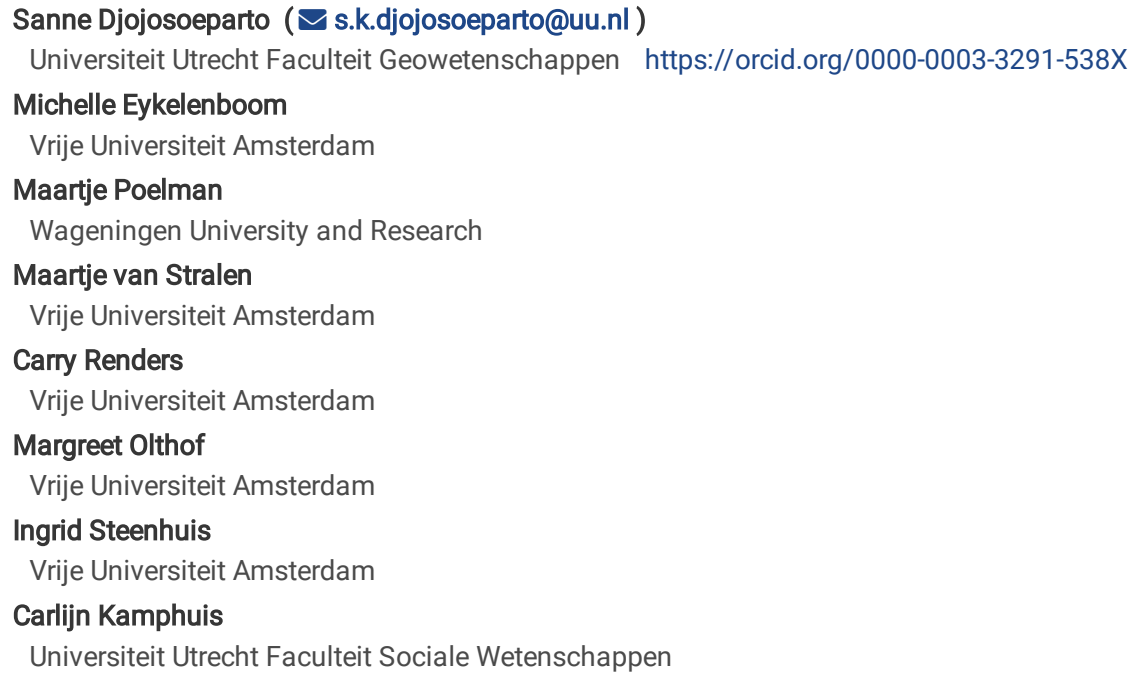




\section{Abstract}

\section{Background}

There are socioeconomic inequalities in overweight and obesity in many European countries. The introduction of a sugar-sweetened beverages (SSB) tax may contribute to a reduction of these inequalities. However, little is known about the views of various stakeholder groups, involved in the decision-making process of implementing an SSB tax, on the potentially different effects of an SSB tax on lower and higher socioeconomic groups. This study aims to gain insight into the perceptions of stakeholder groups in the Netherlands on (1) the effects of an SSB tax on the budgets of lower and higher socioeconomic groups and (2) the impact of an SSB tax on socioeconomic inequalities in dietary intake and health.

\section{Methods}

A qualitative semi-structured interview study was conducted between March and May 2019 with 27 participants from various stakeholder groups (i.e. health and consumer organizations, health professional associations, trade associations, science, advisory bodies, ministries and parliamentary parties) in the Netherlands. Data were analyzed using a thematic content approach.

\section{Results}

Participants, from all stakeholder groups, indicated that an SSB tax would have a larger impact on the budgets of lower socioeconomic groups. Participants, from all stakeholder groups (except trade associations), mentioned an SSB tax could have greater health benefits among lower socioeconomic groups as they often have a higher SSB consumption and are more likely to be overweight or obese. Some participants (from science, a health and consumer organization, and a health professional association) mentioned that an SSB tax may have no or adverse health effects among lower socioeconomic groups (e.g. compensation of lower SSB consumption with other unhealthy behaviours). Some participants (from science and a health and consumer organization) emphasised an SSB tax should only be introduced when accompanied by other interventions (e.g. educational efforts, offering healthy alternatives), to make it easier for lower socioeconomic groups to lower their SSB consumption in response to an SSB tax, and to prevent adverse health effects.

\section{Conclusions}

Participants believed an SSB tax could contribute to a reduction in socioeconomic inequalities in dietary intake and health. However, additional interventions facilitating the reduction of SSB consumption in lower socioeconomic groups were recommended.

\section{Background}

According to the World Health Organization (WHO), obesity has nearly tripled since 1975 worldwide. ${ }^{(1)}$ In 2016 , more than 1.9 billion adults (39\% of the global population) were overweight, over 650 million of whom (13\% of the global population) were obese. ${ }^{(1)}$ In the WHO European Region, $58 \%$ of the adult population was overweight in 2014. ${ }^{(2)}$ People with a lower educational level are more likely to be overweight and obese than those with a higher educational level in most European countries, ${ }^{(3)}$ and a widening of absolute socioeconomic inequalities in obesity prevalence has been observed in 15 European countries. (4)

Unhealthy diets are a leading risk factor for overweight and obesity, as well as for other diet-related non-communicable diseases, such as cardiovascular diseases, type 2 diabetes, musculoskeletal disorders (especially osteoarthritis) and some cancers. ${ }^{(1,2,5)}$ Unhealthy diets are characterized by excessive intake of saturated fats, trans fats, sugar, and salt, largely due to increased consumption of highly processed, energy-dense manufactured foods, like sugarsweetened beverages (SSBs). Previous studies have shown that unhealthy diets are more common among people with a lower socioeconomic position (SEP) (6), and that lower socioeconomic groups consume more SSBs than higher socioeconomic groups. $(7,8,9,10)$ A study of 11 -year old children revealed that children with a low SEP consumed 0,63 litres of SSBs more per week than children with a high SEP. ${ }^{(10)}$

The WHO Commission on Ending Childhood Obesity noted that fiscal policies may encourage consumers - and especially those on low income - to make healthier choices. ${ }^{(11)}$ The WHO sees taxation of SSBs as the most feasible fiscal policy tool to implement on a large scale. SSBs are an easy-to-define category of products that are dense in energy and poor in nutrients, which have healthier and less expensive substitutes (e.g. water). ${ }^{(12)}$ Furthermore, SSBs are a major driver of increased weight gain and type 2 diabetes which provides a rationale for government action. ${ }^{(13,14)}$

As lower socioeconomic groups are more sensitive to price increases ${ }^{(15)}$ and consume more SSBs than higher socioeconomic groups, an SSB tax may have larger positive effects on the healthfulness of diets of lower socioeconomic groups. ${ }^{(12,15)}$ Evidence from countries in which an SSB tax already has been implemented shows a decrease in SSB consumption $(13,16,17)$, with a greater reduction among those with a lower SEP. ${ }^{(8)}$ As a result, an SSB tax, as a component of a comprehensive approach, could contribute to reduced dietary inequalities, and ultimately, improved health equity. ${ }^{(6,12,18,19)}$

Although evidence suggests an SSB tax may have the potential to be pro-equity, this does not imply that all stakeholders involved in the decision-making process about whether or not to implement an SSB tax are sensitive to this argument. This could slow down or even block the decision-making process. ${ }^{(20,21)}$ Various studies reported concerns among stakeholders about the regressive effect of an SSB tax; the tax would have a larger impact on the (often) smaller budgets of lower socioeconomic groups, which is considered unfair. ${ }^{(22)}$

To date, little is known about the perspectives of various stakeholder groups (e.g. health professional associations, scientists, policy makers) regarding the effects of an SSB tax on the budgets and diets of different socioeconomic groups in the Netherlands. These perspectives would lead to a greater 
understanding of existing views on how an SSB tax could contribute to socioeconomic inequalities in dietary intake and health. Furthermore, these insights are especially relevant when governments would consider to implement an SSB tax, given the persistence of health inequalities in many European countries. This study aims to gain insight into the perceptions of different stakeholder groups in the Netherlands on (1) the differential effects of an SSB tax on the budgets of lower and higher socioeconomic groups and (2) the impact of an SSB tax on socioeconomic inequalities in dietary intake and health.

\section{Methods}

\section{Study design and participant recruitment}

We conducted a qualitative semi-structured interview study including a wide range of Dutch stakeholders from various professional backgrounds and sectors: health and consumer organizations, health professional associations, advisory bodies, science, trade associations, ministries and parliamentary parties (Table 1).

To recruit participants, we used purposive sampling combined with snowball sampling. We approached a total of 46 stakeholders, of whom 11 declined and 8 did not reply to reminder e-mails, nor did return our calls (see Table 1 for reasons for non-participation). A total of 25 semi-structured interviews were held with in total 27 participants. One interview was held with two participants that represented two trade associations and one interview was held with two participants that represented one advisory body.

\section{Interview procedure}

Data were collected in March, April and May 2019. Qualitative face-to-face interviews were held in Dutch, using a semi-structured interview guide, by two members of the research team (ME and SD). The questions in this interview guide were developed by using topics identified in the literature. ${ }^{(22,23,24)}$ The interview guide included questions about the advantages and disadvantages of the introduction of an SSB tax in general, and included more specific questions about the differential effects of an SSB tax on different socioeconomic groups:

- In your opinion, are there specific groups of people who are financially more or less affected by an SSB tax?

- In your opinion, are there specific groups of people for whom an SSB tax would be more or less effective in reducing overweight and obesity?

In response to these questions, participants shared a wealth of information on the effects of an SSB tax on the budgets, dietary intake, and health of different socioeconomic groups, as described in this manuscript. Results about stakeholder views on taxation of SSBs in general and barriers and facilitators that may influence the potential future introduction of an SSB tax in the Netherlands have been submitted for publication elsewhere (Eykelenboom M, Djojosoeparto SK, van Stralen MM et al).

The interviews lasted 25 to 90 minutes, were audio-recorded, and transcribed verbatim by two researchers (ME and SD). A summary of the interview was sent to every participant to check for accuracy. Anonymity of the participants was assured by using identification numbers instead of names.

\section{Data analysis}

Two researchers (ME and SD) analysed the interview transcripts with MAXQDA Qualitative Data Analysis Software (version 2018.2), using a thematic content approach. ${ }^{(25)}$ ME and SD coded the first four interview transcripts inductively line-by-line and independent of each other. Subsequently, ME and SD discussed the emergent themes until consensus was reached. This led to the development of an initial thematic map which was used for coding the next interview transcripts by either ME or SD. During the coding, ME and SD discussed the themes repetitively with each other to review themes for coherence, refine existing themes, identify new themes, and recode some data extracts.

All interview fragments that were coded with either 'health inequality or 'income inequality' were further analysed for this paper. Fragments in which participants talked about specific perspectives/topics in relation to these two themes have been copied from the transcripts and pasted into a separate document, including the ID-number of the participant who brought this up. The researchers checked which stakeholder group the participant belonged to. This document was used to create Table 2, which shows the specific perspectives and topics that have been mentioned. If one or more participants from a certain stakeholder group mentioned a specific topic, this has been indicated with a ' $X$ ' in Table 2. All quotes in this paper have been translated from Dutch into English.

\section{Results}

In general, participants from all stakeholder groups, except from trade associations, thought that an SSB tax would reduce purchases and consumption of SSBs (a description of the views of Dutch stakeholders on the taxation of SSBs in general, and on the factors influencing its potential future introduction in the Netherlands, has been submitted for publication elsewhere ; Eykelenboom M, Djojosoeparto SK, van Stralen MM et al.). Some scientists and participants from trade associations were inconclusive of this reduction. Furthermore, participants shared their views on how an SSB tax would affect the budgets and SSB consumption of different socioeconomic groups and impact on inequalities in dietary intake and health. Below we will elaborate on these different views and Table 2 gives an overview of the perspectives of participants of different stakeholder groups.

\section{Differential effects of an SSB tax on the budgets of lower and higher socioeconomic groups}

Participants from all stakeholder groups mentioned that an SSB tax will have a financially regressive effect. Participants (from science and the ministries) reasoned that people with a lower SEP often have a lower income and spend a larger proportion of their income on food purchases. Consequently, an SSB tax 
will have a larger effect on the budgets of people with a lower SEP. Furthermore, participants (from health professional associations, advisory bodies, science, a ministry, and parliamentary parties) reasoned that people with a lower SEP in general consume more unhealthy foods and drinks like SSBs than people with a higher SEP, which could further increase the effect of an SSB tax on their financial situation if they would stick to their usual levels of SSB consumption. There could be a chance that people with a lower SEP will stick to their usual SSB consumption levels, because they can be less capable of and/or willing to change their routines regarding consuming SSBs than people with a higher SEP, as was mentioned by two scientists. A scientist noted '...it is financially unbearable for people when they are not capable to make alternative choices. That is a potential problem.' Another scientist reasoned that when an SSB tax will disproportionally affect the financial situation of people with a lower SEP, this could thus lead to a widening of budgetary inequalities.

However, a few participants, although acknowledging the regressive effect of an SSB tax, were less concerned about possible adverse financial effects. One policy maker referred to evidence which showed that the regressive effect is likely to be marginal for this specific tax, because the absolute price increase is quite low for these relatively inexpensive drinks. A politician mentioned 'if the [SSB] tax increases [the price of SSBs], it works regressive. And that is of course... not the intention. On the other hand, there is the discussion about if healthy eating is more expensive...and that is not the case. Thus... if you eat according to the Dutch Wheel of Five [dietary guidelines] (26) (and then you do not buy cola and chips because they are not included)....you can eat healthy for 5 a 6 euros per day per person. Yes, that includes less [treats] and less cookies .... but those are also the products you do not need'.

\section{The contribution of an SSB tax to socioeconomic inequalities in dietary intake and health}

Participants from all stakeholder groups, except those from trade associations, mentioned the progressive health benefits of an SSB tax. They see it as an advantage rather than a disadvantage that an SSB tax will probably disproportionally affect the budgets and SSB consumption of people with a lower SEP.

Participants (from health professional associations, advisory bodies, science, a ministry, and parliamentary parties) mentioned that people with a lower SEP often have unhealthier dietary behaviour, including a higher consumption of SSBs. According to a few participants (from science) living unhealthier lives among people with a lower SEP may be caused by, for example, less knowledge about healthy behaviour, and by being more vulnerable to and more exposed to an environment that stimulates unhealthy behaviour. Consequently, the prevalence of overweight and obesity is higher among people with a lower SEP and they have a greater risk of experiencing health problems (e.g. type 2 diabetes, cardio vascular disease) than people with a higher SEP according to participants (from health and consumer organizations, a health professional association, science, a ministry, and a parliamentary party). Participants (from health and consumer organizations, science, and a parliamentary party) reasoned that an SSB tax will increase the price of SSBs and will therefore stimulate people, especially people with a lower SEP, to buy and consume fewer SSBs and make more alternative, healthier choices, which will thus positively contribute to their health. A politician noted 'from a lot of research, it appears that people with a lower socioeconomic position......live unhealthier lives. Thus, if...people with less money to spend choose for more inexpensive drinks which also contain less sugar, that is, I think what we would want.'

Scientists mentioned that an SSB tax could be especially effective for the health of people with a lower SEP, who are more difficult to reach by other interventions. One of these scientists noted 'The whole environment we are living in invites to unhealthy behaviour...for which [lower socioeconomic] groups are more vulnerable. If they would like to improve the health of all people, and especially of these [lower socioeconomic] groups, this [an SSB tax] is an intervention that could be potentially effective. More than an intervention that depends on individual behavioural change or motivation."

Thus, according to a number of participants, an SSB tax stimulating people to buy fewer SSBs will contribute positively to the health of people in general, but even more to the health of people with a lower SEP. Consequently, SSB taxation may contribute to a decrease in socioeconomic inequalities in health, like a participant from an advisory body noted 'prevention aims to decrease socioeconomic health inequalities...this is an advantage [of an SSB tax], as this is just what it does'. A participant from a health professional association mentioned 'unhealthy [foods] should be made unattractive for everybody. And the rich people will continue buying it, I can believe that. However, especially in the lower socioeconomic groups, that [unhealthy eating] is a big problem in the Netherlands. ....In the lower socioeconomic groups differences will be made and that is I think what is needed.'

In contrast to the arguments above, some participants mentioned an SSB tax could also have no or adverse health effects. As was also noted in the paragraph about the financial effects of an SSB tax, two scientists mentioned that people with a lower SEP can be less capable of and/or willing to change their routines regarding consuming SSBs than those with a higher SEP. One of these scientists argued that 'if people are stuck in certain behavioural routines, they can't adjust these very easily. And then the point is, how strong is the incentive? Is the incentive strong enough to break through a habit? These scientists mentioned also that people with a lower SEP can be less willing to change their SSB consumption because they fear that their children will not be happy when they can drink less SSBs, or because they feel that drinking less SSBs would lower their quality of life. As a scientist mentioned: ' $A$ cola is just one of the last things they [people with a lower SEP] could award themselves with'. Thus, [the implementation of an SSB tax] is not contributing to their quality of life, because it is a larger proportion of their income and it could increase the socioeconomic differences'.

A possible adverse effect of an SSB tax that was raised by a few participants is the possibility that a reduced SSB consumption will be compensated by an increased consumption of other unhealthy products. One participant from a health professional association mentioned: 'People who cannot afford it [their usual level of SSB consumption] will maybe start doing [other] things which are 'bad' [for their health]. One participant from a health and consumer organization mentioned that 'stop drinking SSBs is, I think, for everybody a very good step for health, but on the other hand, if you compensate that with other unhealthy behaviour, that is of course not desirable'.

When lower socioeconomic groups do not decrease their SSB consumption, or compensate a reduced SSB consumption with eating other unhealthy treats (e.g. more sweets or chocolate bars), and higher socioeconomic groups will reduce their SSB consumption in response to an SSB tax, two participants (a scientist and a professional affiliated with a health professional association) reasoned this could lead to a widening of socioeconomic inequalities in dietary intake and health. 
To make it easier for lower socioeconomic groups to lower their SSB consumption in response to an SSB tax, and to prevent adverse effects, some participants emphasized that the implementation of an SSB tax should be accompanied by other interventions. According to a participant from a health and consumer organization, informing people, creating support for an SSB tax, and offering healthier alternatives that are affordable would be essential conditions for its success. One scientist mentioned further: '... if you don't ensure at the same time a decrease in prices of healthy products, then you are disproportionally affecting [lower socioeconomic] group[s], because they cannot even afford themselves.... a cola. Thus, you have to make sure there are attractive [healthy] alternatives [...] which are festive and cheerful'. Another scientist mentioned some form of compensation for people with a lower SEP as an additional measure accompanying the implementation of an SSB tax. This could be done by investing the revenues of the SSB tax in a fund from which measures can be paid that benefit the health of people with a lower SEP.

\section{Discussion}

In this study, we aimed to gain insight into the perceptions of different stakeholder groups in the Netherlands on (1) the differential effects of an SSB tax on the budgets of lower and higher socioeconomic groups and (2) the impact of an SSB tax on socioeconomic inequalities in dietary intake and health.

Participants, from all stakeholder groups, mentioned that an SSB tax would have a regressive financial effect, i.e. a larger impact on the budgets of lower socioeconomic groups. As a result of cutting down on SSBs, participants, from all stakeholder groups except trade associations, indicated an SSB tax could have greater health benefits among lower socioeconomic groups, who often have unhealthier diets (including a higher SSB consumption) and are more likely to be overweight or obese. Some participants (from science, a health and consumer organization, and a health professional association) indicated that an SSB tax could have no effect or adverse health effects for lower socioeconomic groups (e.g. compensation of lower SSB consumption with other unhealthy behaviours). Some participants (from science and a health and consumer organization) emphasized that an SSB tax should only be introduced when accompanied by other interventions, to make it easier for lower socioeconomic groups to lower their SSB consumption in response to an SSB tax, and to prevent adverse health effects. Examples of these interventions are educational efforts, offering healthy alternatives, decreasing the prices of healthy products, and investing the revenue of the tax in favour of people with a lower SEP.

The regressive financial effect as perceived by participants from all stakeholder groups in our study is in line with the literature. The regressive burden of taxes on food and beverage products was highlighted in 27 studies of a systematic review of empirical studies on health taxes ${ }^{(27)}$. In another systematic review on the impact of an SSB tax according to SEP ${ }^{(8)}$, five studies also reported that an SSB tax is consistently financially regressive but, like a policy maker in our study noted, only to a small degree because the absolute price increase is quite low. A politician in our study mentioned that this regressive effect does not need to occur when people eat healthy according to the Dutch dietary guidelines and consequently do not buy SSBs. However, a study in the Netherlands revealed energy density was inversely related with energy costs, implying that healthier diets cost more. ${ }^{(28)}$

The progressive health effect of an SSB tax as perceived by participants in our study is also corresponding with the literature. Seven modelling studies in a review on the impact of an SSB tax according to SEP ${ }^{(8)}$ reported either similar reductions in body weight across socioeconomic groups or greater reductions for lower socioeconomic groups. Another systematic review of empirical studies on health taxes ${ }^{(27)}$ included 15 studies which found that public health impacts are likely to be the largest for lower socioeconomic groups. In contrast, two studies in this review did not find significant differences in health impacts between socioeconomic groups. Therefore, the authors concluded that taxes on unhealthy food and beverages may contribute to a reduction in socioeconomic health inequalities, but that more research is needed.

Several authors in the literature have addressed the question whether the regressive burden of an SSB tax would be exceeded by the benefits of an SSB tax in terms of health. $(27,29,30,31,32)$ The outcome of this question depends on the behaviour of consumers: if people with a lower SEP substantially reduce their SSB consumption in response to an SSB tax, then the health benefits compared to the financial burden are relatively larger, making the tax less regressive. On the other hand, if a tax does not lead to a considerable reduction of SSB consumption among people with a lower SEP, then the benefits compared to the financial burden are relatively small. ${ }^{(31,32)}$ The review of empirical studies by Wright et al. ${ }^{(27)}$ states that available research does not sufficiently address the question whether the overall benefits of food and beverage taxes (i.e. reducing consumption of unhealthy products) exceed the financial burden for people who do not reduce their consumption.

Regarding the possibility that an SSB tax has no effect, participants in our study noted that people may not be able/willing to change their SSB consumption routines. A participant in our study emphasized that the incentive has to be strong to make people change their SSB consumption routines, especially among people with a lower SEP. This corresponds with results in the systematic review of Wright et.al (27), which states that lower and incremental taxes are less likely to achieve behaviour changes and that evidence shows a tax of at least $20 \%$ is needed to reduce the consumption of unhealthy products. (27) Participants in our study also generally recommended to implement a tax on all beverages with sugar of at least 20\% (publication about Dutch stakeholders views on the taxation of SSBs in general, and on the factors influencing its potential future introduction in the Netherlands; Eykelenboom M, Djojosoeparto SK, van Stralen MM et al.).

A possible adverse health effect of an SSB tax noted by participants in our study is the substitution between SSBs and other unhealthy food and beverages, which is mentioned in the literature as well. $(27,31,33,34,35,36,37)$ Various authors have highlighted the difficulties in monitoring these behavioural responses $(31$,

${ }^{33}$, but we have also found some studies which examined these substitution patterns. Studies in the United States showed that the reduction in soda consumption is completely offset by increases in consumption of other high calorie drinks and therefore did not lead to significant reductions in people's body weight. ${ }^{(27,34,35)}$ However, Fletcher et.al ${ }^{(35)}$ also mentioned that this substitution does not necessarily have to be negative in terms of health outcomes, when people substitute the SSBs for example with whole milk (which is also high in calories, but more nutritious and does not contain added sugar). Thus, even if 
taxation does not lower obesity rates, SSB taxes could combat poor health outcomes (e.g. type 2 diabetes, cardiovascular risk, poor dental health) associated with high levels of added sugar consumption. Studies using simulation models showed that an SSB tax could result in a decrease in energy (calories) purchases ${ }^{(36)}$ and consumption ${ }^{(37)}$ but would not result in substitution to sugary foods. ${ }^{(36)}$ One study showed that the predicted decline in calorie intake was larger for lower socioeconomic groups than for higher socioeconomic groups. ${ }^{(37)}$ In contrast, this study found that an increase in SSB prices (half-cent per ounce) would lead to an increase in sodium and fat intake as a result of product substitution. ${ }^{(37)}$ Given the few and diverse studies that examined SSB substitution patterns and the difficulty of monitoring these patterns, more empirical research is needed to be able to substantiate the substitution patterns described by the participants in our study.

Participants in our study indicated that when an SSB tax has no effect or adverse health effects (i.e. people not being able to change their SSB consumption routines and/or substituting SSBs for other unhealthy foods and beverages) this could lead to an increase in health inequalities. However, evidence showing that an SSB tax increases health inequalities is scarce. A study in Chile showed a greater decline in consumption of SSBs among people with a higher SEP compared to people with a lower SEP after the introduction of a tax. This may suggest a signalling pathway, where public health messaging discourages SSB consumption, may work more effectively for high socioeconomic groups than low socioeconomic groups. ${ }^{(16)}$ Such a signalling pathway could thus lead to a widening of health inequalities. The systematic review of empirical studies by Wright et.al. ${ }^{(27)}$ included two studies which did not find significant differences in public health impacts between socioeconomic groups, but this would not cause an increase in health inequalities (nor a decrease in health inequalities). Considering the few studies and diverse outcomes, more studies are needed to generate evidence about the contribution of an SSB tax to health inequalities.

To increase the effect of an SSB tax on the health of people with a lower SEP and to prevent that an SSB tax leads to an increase in socioeconomic inequalities in dietary intake and health, some stakeholders in our study suggested to implement additional interventions accompanying the SSB tax. Implementing an SSB tax as part of a comprehensive policy framework has also been recommended in the literature. Previous studies emphasized that additional measures could reduce the regressive nature of health taxes ${ }^{(27)}$, limit the possibility for substitution to unhealthful alternatives ${ }^{(34,35)}$, or are necessary to achieve sustained reductions in SSB consumption ${ }^{(29)}$. For example, a tax combined with a subsidy for fruits and vegetables ${ }^{(27)}$ and an extension of an SSB tax to a tax that taxes all caloric sweeteners could be more effective than a tax in isolation ${ }^{(35)}$. The WHO recommends comprehensive action plans at the country level that combine taxation, restriction of marketing of sugary products to children, and education. ${ }^{(38)}$ Using revenue to fund initiatives benefiting people with greater disadvantage was recommended by a study conducted in Australia on modelled health benefits of an SSB tax across socioeconomic groups. ${ }^{(30)}$ In a study exploring public acceptability of an SSB tax in the Netherlands, less than half of the Dutch adults ( $\left.\mathrm{n}=500\right)$ were in favour of an SSB tax in general, but if the revenue is used for health initiatives more than half of the Dutch adults were in favour of an SSB tax. ${ }^{(39)}$ Support for an SSB tax was significantly lower among people with a lower educational level than people with a higher educational level.

Furthermore, the World Cancer Research Fund International (WCRF) recommends modelling the impact of SSB taxes on different socioeconomic groups, to design an SSB tax that is fit-for-purpose and context appropriate, and to increase public and political support for the tax. ${ }^{(40)}$ The Dutch Scientific Council for Government Policy proposes a perspective in which policymakers should not focus on decreasing health inequalities, but on where the greatest possible health gains lie, and how to keep health losses to a minimum. ${ }^{(41)}$ This means a greater focus on people with the greatest health disadvantage.

\section{Strengths \& limitations}

The main strength of this study is that it is one of the first studies to provide insights into the perspectives of various stakeholder groups (parliamentary parties, ministries, science, health and consumer organizations, health professional associations, advisory bodies, trade associations) regarding the effects of an SSB tax on different socioeconomic groups. Another strength of this study is the use of a qualitative design, as the interviews provided in-depth and rich information that could not have been gained through quantitative methods. A limitation could be that the interviews were held by two different researchers (ME and SD). ME conducted interviews with stakeholders from science, advisory bodies, trade associations, health professional associations, and health and consumer organizations. SD conducted interviews with stakeholders from parliamentary parties, ministries, and trade associations. We attempted to prevent interview bias using an interview guide. Lastly, it should be kept in mind that the findings of this study were restricted to the opinions of 27 stakeholders in the Netherlands and a substantial number of invited stakeholders $(n=19)$ declined to participate. Therefore, we are not certain if all opinions have been included in this study.

\section{Conclusions}

Participants, from all stakeholder groups, mentioned that an SSB tax would have a larger impact on the budgets of people with a lower SEP. As a result, lower socioeconomic groups who often have unhealthier diets (including a higher SSB consumption) and are more likely to be overweight and obese, may be more likely of cutting down on SSBs. Therefore, participants, from all stakeholder groups except trade associations, indicated an SSB tax could have greater health benefits among lower socioeconomic groups than higher socioeconomic groups and has the potential to be pro-equity. However, to be effective and to prevent potential adverse health effects, some participants (from science and a health and consumer organization) stressed the importance of additional interventions facilitating the reduction of SSB consumption in lower socioeconomic groups. These interventions could also increase support for an SSB tax from several stakeholder groups $(39,40)$ and with that facilitate the decision-making process.

Further research is required to gain more insights into the opinions of certain stakeholder groups regarding the effects of an SSB tax on different socioeconomic groups. It would also be interesting to have more studies that statistically test differences in outcomes following an SSB tax between different socioeconomic groups, to substantiate the arguments and generate more evidence.

\section{Abbreviations}


SEP, socioeconomic position

SSB, sugar-sweetened beverages

WCRF, World Cancer Research Fund International

WHO, World Health Organization

\section{Declarations}

Ethics approval and consent to participate

The study was conducted according to the ethical standards declared in the Declaration of Helsinki. In accordance with the Dutch Medical Research Involving Human Subjects Act, approval of the study by the Medical Ethics Committee was not required. Written informed consent was obtained from all participants before each interview.

Consent for publication

Not applicable.

Availability of data and materials

The transcripts generated and analyzed during the current study are not publicly available due to ethical restrictions protecting participant confidentiality.

Competing interests

The authors declare that they have no competing interests.

Funding

Authors' contributions

$\mathrm{ME}$, in collaboration with $\mathrm{CK}, \mathrm{MP}, \mathrm{MS}, \mathrm{CR}$, IS and MO, formulated the research questions and designed the study.

ME and SD conducted the interviews. ME interviewed participants from the stakeholder groups: health and consumer organizations $(\mathrm{n}=3)$, health professional associations $(n=3)$, science $(n=9)$, trade associations $(n=3)$, and advisory bodies $(n=1)$. SD interviewed participants from the stakeholder groups: ministries $(n=3)$, parliamentary parties $(n=3)$, and trade associations $(n=1)$. ME and SD carried out the analysis of the interview transcripts.

SD, together with CK and MP, had the lead in writing this manuscript. ME, IS, MO, CR and MS critically reviewed the manuscript. All authors read and approved the final manuscript.

Acknowledgements

We would like to thank all the stakeholders who participated in our interview study for their time, efforts and valuable contributions to this study.

This research is part of the Policy Evaluation Network (PEN) ${ }^{(42)}$, Workpackage 6: https://www.jpi-pen.eu/structure/work-packages.html. PEN is funded by the Joint Programming Initiative: a Healthy Diet for a Healthy Life (JPI-HDHL): https://www.healthydietforhealthylife.eu/, a research and innovation initiative of EU member states and associated countries.

\section{References}

1. World Health Organization. Factsheet Obesity and Overweight. 2020. https://www.who.int/news-room/fact-sheets/detail/obesity-and-overweight. Accessed January 2020

2. World Health Organization, Regional Office for Europe. Better food and nutrition in Europe: a progress report monitoring policy implementation in the WHO European Region. Copenhagen: WHO Regional Office for Europe; 2018.

3. Roskam AJ, Kunst AE, Van Oyen H, Demarest S, Klumbiene J, Regidor E, et al. Comparative appraisal of educational inequalities in overweight and obesity among adults in 19 European countries. Int J Epidemiol 2010; 39 (2): 392-404.

4. Hoffmann K, De Gelder R, Hu Y, Bopp M, Vitrai J, Lahelma E, et al. Trends in educational inequalities in obesity in 15 European countries between 1990 and 2010. Int J Behav Nutr Phys Act 2017; 14:

5. World Health Organization Regional Office for Europe. European Food and Nutrition Action Plan 2015-2020. REGIONAL COMMITTEE FOR EUROPE 64th SESSION. Copenhagen, Denmark, 15-18 September 2014. Copenhagen: WHO Regional Office for Europe; 2014.

6. Turrell G, Vandevijvere S. Socio-economic inequalities in diet and body weight: evidence, causes and intervention options. Public Health Nutr 2015;18 (5): $759-763$

7. World Obesity Federation. The impact of a tax on sugar-sweetened beverages according to socioeconomic position: a systematic review of the evidence. http://s3-eu-west-1.amazonaws.com/wof-files/The_impact_of_a_tax_on_sugar-sweetened_beverages_according_to_socio-economic_position__a_systematic_review_of_the_evidence_.pdf. Accessed January 2020.

Page $7 / 10$ 
8. Backholer, K, Sarink D, Beauchamp A, Keating C, Loh V, Ball K, et al. The impact of a tax on sugar-sweetened beverages according to socio-economic position: a systematic review of the evidence. Public Health Nutr 2016; 19 (17): 3070-3084.

9. Mullie P, Aerenhouts D, Clarys P. Demographic, socioeconomic and nutritional determinants of daily versus non-daily sugar-sweetened and artificially sweetened beverage consumption. Eur J Clin Nutr 2012; 66 (2): 150-155.

10. van Ansem WJ, van Lenthe FJ, Schrijvers CT, Rodenburg G, van de Mheen Socio-economic inequalities in children's snack consumption and sugarsweetened beverage consumption: the contribution of home environmental factors. Br J Nutr 2014; 112 (3): 467-476.

11. World Health Organization. Report of the Commission on Ending Childhood Obesity. Geneva: WHO; 2016.

12. World Health Organization Regional Office for Europe. Using price policies to promote healthier diets. Copenhagen: WHO; 2015.

13. Popkin BM, Hawkes C. Sweetening of the global diet, particularly beverages: patterns, trends, and policy responses. Lancet Diabetes Endocrinol 2016; 4 (2): 174-186.

14. de Ruyter JC, Olthof MR, Seidell JC, Katan MB. A trial of sugar-free or sugar-sweetened beverages and body weight in children. N Engl J Med 2012; 367: 1397-1406.

15. Steenhuis, IH, Waterlander WE, \& de Mul A. Consumer food choices. The role of price and pricing strategies. Public Health Nutr. $2011 ; 14$ (12): $2220-2226$.

16. Teng AM, Jones AC, Mizdrak A et. Al (2019). Impact of sugar-sweetened beverage taxes on purchases and dietary intake: Systematic review and metaanalysis. Obes Rev 2019; 20 (9), 1187-1204.

17. Powell, LM, Chriqui JF, Khan T, Chaloupka FJ. Assessing the potential effectiveness of food and beverage taxes and subsidies for improving public health: a systematic review of prices, demand and body weight outcomes. Obes Rev 2013; 14: 110-128.

18. Mytton O, Clarke D, Rayner M. Taxing unhealthy food and drinks to improve health. Br Med J 2012; 344: e2931.

19. Eyles H, Mhurchu CN, Nghiem N, Blakely T. Food pricing strategies, population diets, and noncommunicable disease: a systematic review of simulation studies. PLoS Med 2012; 9 (12): e1001353.

20. Rajagopal S, Barnhill A, Sharfstein The evidence-and acceptability-of taxes on unhealthy foods. Isr J Health Policy Res $2018 ; 7: 68$.

21. Saxena A, Koon AD, Lagrada-Rombaua L, Angeles-Agdeppa I, Johns B, Capanzana Modelling the impact of a tax on sweetened beverages in the Philippines: an extended cost-effectiveness analysis. Bulletin of the World Health Organization; 2019; 97 (2): 97-107.

22. Eykelenboom M, van Stralen MM, Olthof MR, Schoonmade LJ, Steenhuis IHM, Renders CM. Political and public acceptability of a sugar-sweetened beverages tax: a mixed-method systematic review and meta-analysis. Int J Behav Nutr Phys Act 2019; 16 (1):

23. Signal LN, Watts C, Murphy C, Eyles H, Mhurchu CN. Appetite for health-related food taxes: New Zealand stakeholder views. Health Promot Int 2018,33 (5): 791-800.

24. Tamir O, Cohen-Yogev T, Furman-Assaf S, Endevelt R. Taxation of sugar sweetened beverages and unhealthy foods: a qualitative study of key opinion leaders' views. Isr J Health Policy Res 2018; 7(1): 43.

25. Green J, Thorogood N. Qualitative methods for health research. London: SAGE; 2018.

26. Netherlands Nutrition Centre. The Wheel of Five. Factsheet. 2017. https://mobiel.voedingscentrum.nl/Assets/Uploads/voedingscentrum/Documents/Professionals/Pers/Factsheets/English/Fact\%20sheet\%20The\%20Wh Accessed: January 2020.

27. Wright A, Smith KE, Hellowell M. Policy lessons from health taxes: a systematic review of empirical studies. BMC public health $2017 ; 17$ (1): 583.

28. Waterlander WE, de Haas WE, van Amstel I, Schuit AJ, Twisk JWR, Visser M, et al. Energy density, energy costs and income - how are they related? Public Health Nutr 2010; 13(10): 1599-608.

29. Basu S, Madsen K. Effectiveness and equity of sugar-sweetened beverage taxation. PLoS Med 2017;14 (6): e1002327.

30. Lal A, Mantilla-Herrera AM, Veerman L, Backholer K, Sacks G, Moodie M, et.al. Modelled health benefits of a sugar-sweetened beverage tax across different socioeconomic groups in Australia: A cost-effectiveness and equity analysis. PLoS Med 2017; 14(6): e1002326.

31. Allcott H, Lockwood BB, Taubinsky D. Should We Tax Sugar-Sweetened Beverages? An Overview of Theory and Evidence. J Econ Perspect 2019; 33 (3): 202-227.

32. Lockwood B. Do sin taxes really change consumer behavior? Feb 10, 2017. https://knowledge.wharton.upenn.edu/article/do-sin-taxes-really-changeconsumer-behavior/. Accessed January 2020.

33. L Cornelsen, R Green, R Turner, Dangour AD, Shankar B, Mazzocchi M, et al. What happens to patterns of food consumption when food prices change? Evidence from a systematic review and meta-analysis of food price elasticities globally. Health Econ 2015; 24: 1548-1559.

34. Fletcher JM, Frisvold DE, Tefft N. The Effects of Soft Drink Taxes on Child and Adolescent Consumption and Weight Outcomes. J Public Econ 2010; 94 (11-12): 967-974.

35. Fletcher JM, Frisvold D, Tefft N. Substitution Patterns Can Limit the Effects of Sugar-Sweetened Beverage Taxes on Obesity. Prev Chronic Dis 2013;10: e18.

36. Finkelstein EA, Zhen C, Bilger M, Farooqui AM, Todd JE. Implications of a Sugar-Sweetened Beverage (SSB) Tax When Substitutions to Non-Beverage Items Are Considered. J Health Econ 2013; 32: 219-239.

37. Zhen C, Finkelstein EA, Nonnemaker J, Karns S, Todd JE. Predicting the Effects of Sugar-Sweetened Beverage Taxes on Food and Beverage Demand in a Large Demand System. Am J Agric Econ 2014; 96(1): 1-25.

38. World Health Organization. Taxes on sugary drinks: why do it? 2017. https://apps.who.int/iris/bitstream/handle/10665/260253/WHO-NMH-PND16.5Rev.1eng.pdf;jsessionid=C722CA055BDB0AB2BA6A55E6D8652990?sequence=1. Accessed January 2020.

Page $8 / 10$ 
39. Eykelenboom M, van Stralen MM, Olthof MR, Renders CM, Steenhuis IHM. Public acceptability of a sugar-sweetened beverage tax and its associated factors in the Netherlands. Public Health Nutr 2020; doi: https://doi.org/10.1017/S1368980020001500.

40. World Cancer Research Fund International. Building momentum: lessons on implementing a robust sugar sweetened beverage tax. 2018. wcrf.org/buildingmomentum. https://www.wcrf.org/sites/default/files/PPA-Building-Momentum-Report-WEB.pdf. Accessed January 2020.

41. Broeders, DWJ., Das HD, Jennissen RPW, Tiemeijer WL, de Visser M. Van verschil naar potentieel: een realistisch perspectief op de sociaaleconomische gezondheidsverschillen [From disparity to potential: A realistic perspective on socio-economic health inequalities]. WRR (Dutch Scientific Council) Policy Brief 7. 2018. The Hague: WRR.

42. Lakerveld J, Woods C, Hebestreit A, Brenner H, Flechtner-Mors M, Harrington JM, et al. Advancing the evidence base for public policies impacting on dietary behaviour, physical activity and sedentary behaviour in Europe: The Policy Evaluation Network promoting a multidisciplinary approach. Food Policy. Published online: 5 March 2020. https://doi.org/10.1016/j.foodpol.2020.101873

\section{Tables}

Table 1. Study participants

\begin{tabular}{|c|c|c|c|}
\hline $\begin{array}{l}\text { Stakeholder } \\
\text { Group }\end{array}$ & $\begin{array}{l}\text { Participants } \\
\text { approached } \\
(n=46)\end{array}$ & Participants declined $(n=19)$ & Participants included $(n=27)$ \\
\hline $\begin{array}{l}\text { Parliamentary } \\
\text { parties }\end{array}$ & 10 & $\begin{array}{l}\text { No response }(n=2) \\
\text { No time }(n=1) \\
\text { No reason }(n=4)\end{array}$ & Members of the Dutch parliament $(n=3)$ \\
\hline Ministries & 8 & $\begin{array}{l}\text { No response }(n=2) \\
\text { Insufficient knowledge on } \\
\text { taxation of SSBs according to } \\
\text { the stakeholder }(n=1) \\
\text { No reason }(n=2)\end{array}$ & Policymakers from various ministries $(n=3)$ \\
\hline $\begin{array}{l}\text { Advisory } \\
\text { bodies }\end{array}$ & 4 & $\begin{array}{l}\text { No response }(n=1) \\
\text { Insufficient knowledge on } \\
\text { taxation of SSBs according to } \\
\text { the stakeholder }(n=1)\end{array}$ & Representatives of a governmental, non-profit advisory body $(n=2)$ \\
\hline Science & 10 & No time $(=1)$ & $\begin{array}{l}\text { Scientists in the field of obesity prevention, nutrition and health, preventive dentistry, } \\
\text { behavioural science, health economics, tax law, political science, medical ethics or } \\
\text { social epidemiology }(n=9)\end{array}$ \\
\hline $\begin{array}{l}\text { Trade } \\
\text { associations }\end{array}$ & 5 & No response $(n=1)$ & $\begin{array}{l}\text { Representatives of trade associations for food and beverages manufacturers, } \\
\text { hospitality businesses or the catering industry }(n=4)\end{array}$ \\
\hline $\begin{array}{l}\text { Health } \\
\text { professional } \\
\text { associations }\end{array}$ & 3 & NA & $\begin{array}{l}\text { Representatives of non-governmental, non-profit professional associations of } \\
\text { physicians or dentists }(n=3)\end{array}$ \\
\hline $\begin{array}{l}\text { Health and } \\
\text { consumer } \\
\text { organizations }\end{array}$ & 6 & $\begin{array}{l}\text { No response }(n=2) \\
\text { Insufficient knowledge on } \\
\text { taxation of SSBs according to } \\
\text { the stakeholder }(n=1)\end{array}$ & $\begin{array}{l}\text { Representatives of governmental or non-governmental, non-profit consumer } \\
\text { organizations and health organizations in the field of nutrition and health promotion } \\
(n=3)\end{array}$ \\
\hline
\end{tabular}

\section{Table 2 Perspectives on the effects of an SSB tax on higher and lower socioeconomic groups}

$X$ means: one or more participants in this stakeholder group mentioned the specific topic in an interview 
Stakeholder groups

\begin{tabular}{|c|c|c|c|c|c|c|}
\hline $\begin{array}{l}\text { Health and } \\
\text { Consumer } \\
\text { organizations }\end{array}$ & $\begin{array}{l}\text { Health } \\
\text { professional } \\
\text { associations }\end{array}$ & $\begin{array}{l}\text { Advisory } \\
\text { bodies }\end{array}$ & Science & $\begin{array}{l}\text { Trade } \\
\text { associa }\end{array}$ & $\begin{array}{l}\text { Minis- } \\
\text { tries }\end{array}$ & $\begin{array}{l}\text { Parlia- } \\
\text { mentary } \\
\text { parties }\end{array}$ \\
\hline
\end{tabular}

\section{The differential effects of an SSB tax on}

the budgets of lower and higher socioeconomic groups

An SSB tax is financially regressive

$x$

$x$

$x$

$X$

People with a lower socioeconomic position spend a bigger proportion of their income on food purchases

People with a lower socioeconomic position consume more unhealthy foods/drinks like SSBs

People of lower socioeconomic groups cannot easily change their routines

The regressive effect of an SSB tax is likely very marginal

The regressive effect of an SSB tax does not need to occur

when people eat healthy and consequently don't buy SSBs

The impact of an SSB tax on socioeconomic inequalities

\section{in dietary intake and health}

An SSB tax is progressive in terms of health benefits

People with a lower socioeconomic position have more health problems (overweight, non-communicable diseases)

People with a lower socioeconomic position consume more unhealthy foods/drinks like SSBs

An SSB tax could lead to alternative, healthier choices of lower socioeconomic groups

An SSB tax could be especially effective for the health of people with a lower SEP who are more difficult to reach by

other interventions

People of lower socioeconomic groups cannot easily change their routines

$\begin{array}{llllll}X & X & X & X & X & X \\ X & X & x & x & x \\ & X & X & x & x & x \\ X & & x & & x\end{array}$

$X$

An SSB tax could lead to compensation with other unhealthy behaviour

An SSB tax could lead to a widening of socioeconomic inequalities in dietary intake and health
$X$

$X$ $x$ 